Pacific Journal of Mathematics

NORMAL STRUCTURE IN BANACH SPACES

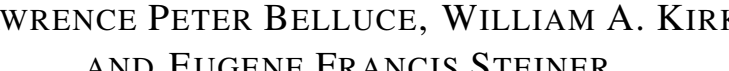




\title{
NORMAL STRUCTURE IN BANACH SPACES
}

\author{
L. P. Belluce, W. A. Kirk and E. F. Steiner
}

A bounded convex subset $K$ of a Banach space $B$ has normal structure if for each convex subset $H$ of $K$ which contains more than one point there is a point $x$ in $H$ which is not a diametral point of $H$. The concept of normal structure (introduced by Brodskii and Milman) and a strengthening of this concept called complete normal structure have been of fundamental importance in some recent investigations concerned with determining conditions on weakly compact $K$ under which the members of any commutative family $\mathscr{T}$ of nonexpansive mappings of $K$ into itself have a common fixedpoint. A more thorough study of these concepts is initiated in the present paper. The theorems obtained primarily concern product spaces composed of spaces which possess normal structure.

Let $K$ be a nonempty, closed, convex, weakly compact subset of the Banach space $B$. It was proved in [1] that if $K$ has normal structure and if $\mathscr{T}$ is a finite family of commutative nonexpansive mappings on $K$ then there is a point $x \in K$ such that $f(x)=x$ for each $f \in \mathscr{T}$. Although we do not know whether this theorem is true in general for infinite families, it is easily seen, as was pointed out in [2], that if the norm of $B$ is strictly convex then the theorem is true if $\mathscr{T}$ is infinite. In [2] the existence of a common fixed-point was established for arbitrary families without the assumption of strict convexity of the norm by the introduction of a strengthening of normal structure called complete normal structure. It was shown in [2] that if $B$ is uniformly convex, or if $K$ is compact, then $K$ has complete normal structure.

We are mainly interested here in providing examples of classes of sets which satisfy the hypotheses of the fixed point theorems of [1] (Theorem 3) and [2] (Theorem 2.1). Our purpose in $\S 2$ is to exhibit such a class of sets $K$ which are not compact and which do not have strictly convex norm. Fixed-point theorems for families of nonexpansive mappings established by De Marr [6] (for $K$ compact) and by F. Browder [4] (for $B$ uniformly convex) do not apply in this class of sets.

In [5], M. M. Day gave an example of a class of reflexive, strictly convex Banach spaces, none of which is isomorphic to any uniformly convex Banach space. We show in $\S 3$ that these spaces do possess normal structure; thus they provide examples of spaces not isomorphic to any uniformly convex space which satisfy the hypothesis of the 
fixed-point theorem of Kirk in [7].

2. Normal structure and complete normal structure. We say that a Banach space has normal structure if each of its bounded convex subsets has normal structure. In this section we first show that the direct sum (with the supremum norm) of two Banach spaces, each with normal structure, itself has normal structure.

THEOREM 2.1. Let $B_{1}$ and $B_{2}$ be Banach spaces with norms $\|-\|_{1}$ and $\|-\|_{2}$, respectively. Let $B=B_{1} \oplus B_{2}$ with the norm of $B$ given by $\|-\|=\sup \left(\|-\|_{1},\|-\|_{2}\right)$. If both $B_{1}$ and $B_{2}$ have normal structure, then $B$ has normal structure.

Proof. Let $K$ be a bounded convex subset of $B$ which contains more than one point and let $p_{i}$ be the natural projection of $B$ onto $B_{i}, i=1,2$. Let $K_{i}=p_{i}(K), i=1,2$. Then $K_{i}$ is a bounded, convex subset of $B_{i}$ and thus possesses normal structure. For $i=1,2$, let $x_{i}$ be a nondiametral point of $K_{i}$. (If $K_{i}$ consists of a single point for some $i$, then the conclusion of the theorem is immediate.)

Select $u_{i} \in p_{i}^{-1}\left(x_{i}\right) \cap K, i=1,2$; then $u_{1}=x_{1} \oplus v$ and $u_{2}=w \oplus x_{2}$ where $v=p_{2}\left(u_{1}\right) \in K_{2}, w=p_{1}\left(u_{2}\right) \in K_{1}$. Set $m=\frac{1}{2}\left(u_{1}+u_{2}\right)=m_{1} \oplus m_{2}$ where $m_{1}=\frac{1}{2}\left(x_{1}+w\right)$ and $m_{2}=\frac{1}{2}\left(v+x_{2}\right)$. Let $z \in K$; then $z=z_{1} \oplus z_{2}$ where $z_{1} \in K_{1}, z_{2} \in K_{2}$. Now $\|m-z\|=\sup \left(\left\|m_{1}-z_{1}\right\|_{1},\left\|m_{2}-z_{2}\right\|_{2}\right)$. But $\left\|m_{1}-z_{1}\right\|_{1}=\left\|\frac{1}{2}\left(x_{1}+w\right)-\frac{1}{2}\left(z_{1}+z_{1}\right)\right\|_{1} \leqq \frac{1}{2}\left(\left\|x_{1}-z_{1}\right\|_{1}+\left\|w-z_{1}\right\|_{1}\right)$. Letting $\delta(-)$ denote the diameter of a set and using the fact that $x_{1}$ is a nondiametral point of $K_{1}$ we see that $\left\|m_{1}-z_{1}\right\|_{1} \leqq \delta\left(K_{1}\right)-\varepsilon_{1}$ for some $\varepsilon_{1}>0$ which does not depend on $z_{1}$. Similarly we have that $\left\|m_{2}-z_{2}\right\|_{2} \leqq \delta\left(K_{2}\right)-\varepsilon_{2}, \varepsilon_{2}>0$ and independent of $z_{2}$. Hence

$$
\|m-z\| \leqq \sup \left(\delta\left(K_{1}\right)-\varepsilon_{1}, \delta\left(K_{2}\right)-\varepsilon_{2}\right) ;
$$

letting $\varepsilon=\min \left(\varepsilon_{1}, \varepsilon_{2}\right)$ we see that

$$
\|m-z\| \leqq \sup \left(\delta\left(K_{1}\right)-\varepsilon, \quad \delta\left(K_{2}\right)-\varepsilon\right)=\delta(K)-\varepsilon .
$$

Thus $m$ is a nondiametral point for $K$ and the theorem is proved.

Before giving the next definition, we introduce the following notation. For subsets $H$ and $K$ of a Banach space $B, H$ bounded, let

$$
\begin{aligned}
& r_{x}(H)=\sup \{\|x-y\|: y \in H\}, \\
& r(H, K)=\inf \left\{r_{x}(H): x \in K\right\}, \\
& \mathscr{C}(H, K)=\left\{x \in K: r_{x}(H)=r(H, K)\right\} .
\end{aligned}
$$

In general, $\mathscr{C}(H, K)$ may be empty, but if it is not, then it consists of precisely those points of $K$ which serve as centers of balls 
of minimal radius, $r(H, K)$, which contain $H$. We remark that if $K$ is weakly compact and convex, and if $H$ is bounded, then $\mathscr{C}(H, K)$ is a nonempty closed convex subset of $K$ (see [2]).

Definition 2.1. Let $K$ be a bounded closed convex subset of a Banach space $B$. We say that $K$ has complete normal structure (c.n.s.) if every closed convex subset $W$ of $K$ which contains more than one point satisfies the following condition:

$\left({ }^{*}\right)$ for every descending net $\left\{W_{\alpha}: \alpha \in A\right\}$ of subsets of $W$ which have the property that $r\left(W_{\alpha}, W\right)=r(W, W)$ for each $\alpha \in A$, it is the case that the closure of $\bigcup_{\alpha \in A} \mathscr{C}\left(W_{\alpha}, W\right)$ is a nonempty proper subset of $W$.

By taking $W_{\alpha} \equiv W$ in the above definition, one sees that if $K$ has complete normal structure then it has normal structure.

Definition 2.2. Let $K$ be a bounded closed convex subset of $B$. We say that a closed convex subset $W$ of $K$ satisfies property $\left({ }^{*}\right)_{q}$ with respect to $K$ if:

$\left({ }^{*}\right)_{q}$ for every descending net $\left\{W_{\alpha}: \alpha \in A\right\}$ of subsets of $W$ which have the property that $r\left(W_{\alpha}, W\right)=r(W, W)$ and $\mathscr{C}\left(W_{\alpha}, K\right) \cap W_{\alpha} \neq \varnothing$, for each $\alpha \in A$, then it is the case that the closure of $\cup \mathscr{C}\left(W_{\alpha}, W\right)$ is a nonempty proper subset of $W$.

Our reason for being interested in property $\left({ }^{*}\right)_{q}$ is the following.

In property $\left({ }^{*}\right)$ of complete normal structure, it is not required that $\mathscr{C}\left(W_{\alpha}, K\right) \cap W_{\alpha} \neq \varnothing$. However, the condition $\left({ }^{*}\right)$ is applied in the proof of Theorem 2.1 of [2] as follows: Each set $W_{\alpha}$ is a fixedpoint set of some nonexpansive mapping $f$ of $K$ into itself (the sets of [2] are labelled differently). It follows that $f\left(\mathscr{C}\left(W_{\alpha}, K\right)\right) \subset \mathscr{C}\left(W_{\alpha}, K\right)$ and, if $K$ also has normal structure, by the theorem of [7], $f$ has a fixed-point in $\mathscr{C}\left(W_{\alpha}, K\right)$. Thus $\mathscr{C}\left(W_{\alpha}, K\right) \cap W_{\alpha} \neq \varnothing$. Thus if $K$ has normal structure, Theorem 2.1 of [2] remains valid (without alteration of the proof) if complete normal structure is replaced by the assumption that every closed convex subset $W$ of $K$ has property $\left({ }^{*}\right)_{q}$ with respect to $K$.

We now investigate the preservation of property $\left({ }^{*}\right)_{q}$ with respect to the taking of finite direct sums.

THEOREM 2.2. Let $B$ be the direct sum, with supremum norm, of the Banach spaces $B_{i}, i=1,2$. For each $i$, let $K_{i}$ be a closed convex weakly compact subset of $B_{i}$. If every closed convex subset of $K_{i}$ satisfies $\left({ }^{*}\right)_{q}$ with respect to $K_{i}, i=1,2$, then every closed convex subset $W$ of $K=K_{1} \oplus K_{2}$ satisfies $\left({ }^{*}\right)_{q}$ with respect to $K$.

Proof. Let $W$ be a closed convex subset of $K$ which contains 
more than one point, and let $\mathscr{W}=\left\{W_{\alpha}: \alpha \in A\right\}$ be a descending net of subsets of $W$ for which $r\left(W_{\alpha}, W\right)=r(W, W)$ and

$$
\mathscr{C}\left(W_{\alpha}, K\right) \cap W_{\alpha} \neq \varnothing, \quad \alpha \in A .
$$

Since $\mathscr{C}\left(W_{\alpha}, K\right) \cap W_{\alpha} \neq \varnothing$ it follows that $\mathscr{C}\left(W_{\alpha}, W\right)=\mathscr{C}\left(W_{\alpha}, K\right) \cap W$. Let $r=r\left(W_{\alpha}, W\right)$ and let $\alpha \in A$ be fixed. Choose $x \in \mathscr{C}\left(W_{\alpha}, W\right)$; then $x=x_{1} \oplus x_{2}$ where $x_{i} \in K_{i}, i=1,2$. For $i=1,2$ let $p_{i}$ denote the natural projection of $B$ onto $B_{i}$. Since $x \in \mathscr{C}\left(W_{\alpha}, W\right)$ it must be the case that $W_{\alpha} \leqq \overline{\mathscr{V}^{\prime}}(x ; r), \overline{\mathscr{V}^{\prime}}(x, r)$ the closure of the ball centered at $x$ with radius $r$. Since the norm in $B$ is the supremum it follows that $p_{i}\left(W_{\alpha}\right) \subseteq \overline{\mathscr{V}^{\prime}}\left(x_{i}, r\right), i=1,2$. Therefore, $r\left(p_{i}\left(W_{\alpha}\right), p_{i}(K)\right) \leqq r$.

We now show that for some $i$, equality must hold. For assume we have $r\left(p_{i}\left(W_{\alpha}\right), p_{i}(K)\right)<r$ for $i=1,2$. Let

$$
\bar{r}=\sup \left\{r\left(p_{1}\left(W_{\alpha}\right), p_{1}(K)\right), r\left(p_{2}\left(W_{\alpha}\right), p_{2}(K)\right)\right\} \text {. }
$$

Select $\bar{x}_{i} \in \mathscr{C}\left(p_{i}\left(W_{\alpha}\right), p_{i}(K)\right)$ and set $\bar{x}=\bar{x}_{1} \oplus \bar{x}_{2} \in K$. It follows that $W_{\alpha} \subseteq \overline{\mathscr{V}}(\bar{x}, \bar{r})$ since for $w=w_{1} \oplus w_{2} \in W_{\alpha}$,

$$
\|\bar{x}-w\|=\sup \left\{\left\|\bar{x}_{1}-w_{1}\right\|,\left\|\bar{x}_{1}-w_{2}\right\|\right\} \leqq \bar{r} .
$$

But this in turn implies $r\left(W_{\alpha}, K\right)=\bar{r}<r$ which is a contradiction. Therefore for each $\alpha \in A$ there is an $i, 1 \leqq i \leqq 2$ such that

$$
r\left(p_{i}\left(W_{\alpha}\right), p_{i}(K)\right)=r=r\left(W_{\alpha}, W\right) .
$$

Now let $\mathscr{W}_{i}=\left\{W_{\alpha} \in \mathscr{W} \mid r\left(p_{i}\left(W_{\alpha}\right), p_{i}(K)\right)=r\right\}, i=1,2$. Suppose $\mathscr{W}_{1}$ is such that for some $W_{\beta} \in \mathscr{W}, W_{\alpha} \in \mathscr{W}_{1}$, there is no $W_{r} \in \mathscr{W}_{1}$ with $W_{\gamma} \subseteq W_{\alpha} \cap W_{\beta}$. Since $\mathscr{W}$ is a net there is then a $W_{r} \in \mathscr{W}_{2}$ such that $W_{r} \subseteq W_{\alpha} \cap W_{\beta}$ and, moreover, for each $W_{\delta} \in \mathscr{W}$, if $W_{\delta} \subseteq W_{r}$ we must have $W_{o} \in \mathscr{W}_{2}$. Let $\mathscr{E}_{2}=\left\{W_{\alpha} \in \mathscr{W}_{2} \mid W_{\alpha} \subseteq W_{\gamma}\right\}$; then $\mathscr{E}_{2} \subseteq \mathscr{W}_{2}, \mathscr{E}_{2}$ is a decreasing net and for all $W_{\delta} \in \mathscr{W}$ there is a $W_{\alpha} \in \mathscr{E}_{2}$ with $W_{\alpha} \subseteq W_{\delta}$. Calling such an $\mathscr{E}$ a filtered subnet we see then that for some $i, 1 \leqq i \leqq 2$, $\mathscr{W}_{i}$ contains a filtered subnet, $\mathscr{E}_{i}$. We may assume $i=1$. Also we have, $\mathscr{C}\left(p_{1}\left(W_{\beta}\right), K_{1}\right) \cap p_{1}\left(W_{\beta}\right) \neq \varnothing$ for each $W_{\beta} \in \mathscr{E}_{1}$. This is clear since for some point $w=w_{1} \oplus w_{2} \in W_{\beta}$ we have $W_{\beta} \subseteq \overline{\mathscr{V}}(w, r)$; hence $p_{i}\left(W_{\beta}\right) \subseteq \overline{\mathscr{V}}\left(w_{i}, r\right)$ where

$$
w_{1} \in p_{1}\left(W_{\beta}\right) \cap \mathscr{C}\left(p_{1}\left(W_{\beta}\right), K_{1}\right) \text {. }
$$

Thus we may apply $\left({ }^{*}\right)_{q}$ to the net $p_{1}\left(\mathscr{E}_{1}\right)=\left\{p_{1}\left(W_{\alpha}\right) \mid W_{\alpha} \in \mathscr{E}_{1}\right\}$ in $B_{1}$, thereby concluding that the closure of $H_{1}=\bigcup_{W_{\beta} \in \mathscr{E}_{1}} \mathscr{C}\left(p_{1}\left(W_{\beta}\right), p_{1}(W)\right)$ is a proper subset of $p_{1}(W)$. Select a point $x_{1} \in p_{1}(W)$ but not in the closure of $H_{1}$. Then there is a number $\varepsilon>0$ such that

$$
\inf _{W_{\beta} \in \mathscr{E}_{1}}\left\{\left\|x_{1}-z_{1}\right\| \mid z_{1} \in \mathscr{C}\left(p_{1}\left(W_{\beta}\right), p_{1}(W)\right)\right\}>\varepsilon .
$$


Choose $x \in W$ so that $p_{1}(x)=x_{1}$; then the above implies

$$
\inf \left\{\|x-z\| \mid z \in \mathscr{C}\left(W_{\alpha}, W\right)\right\}>\varepsilon .
$$

(Here we use the fact that $\mathscr{E}_{1}$ is a filtered subnet of $\mathscr{W}$.) From this we conclude that $x$ is not in the closure of $\bigcup_{\alpha \in A} \mathscr{C}\left(W_{\alpha}, W\right)$, completing the proof.

Consequently we can now manufacture examples of convex sets in spaces without strictly convex norm to which the fixed-point theorems of [1], [2], [7] apply, but in which others do not. For example, let $M_{2}^{(1)}$ denote the two-dimensional Minkowski $p$-space for $p=1$. Points of $M_{2}^{(1)}$ are pairs $\left(x_{1}, x_{2}\right)$ of real numbers with

$$
\left\|\left(x_{1}, x_{2}\right)\right\|=\left|x_{1}\right|+\left|x_{2}\right| \text {. }
$$

This space is not strictly convex, but it is reflexive. Let $K_{1}$ denote the unit ball in $M_{2}^{(1)}$ and $K_{2}$ the unit ball in the Hilbert space $l_{2}$. It has already been proved [2] that bounded closed convex subsets of uniformly convex spaces and compact convex subsets of arbitrary Banach spaces have complete normal structure. Since complete normal structure implies normal structure, $K_{1}$ and $K_{2}$ also have normal structure. Thus by Theorems 2.1 and 2.2, $K=K_{1} \oplus K_{2}$ is a closed convex noncompact subset of $B=M_{2}^{(1)} \oplus l_{2}$ which has normal structure and in which every closed convex subset satisfies $\left({ }^{*}\right)_{q}$, but in which the norm is not strictly convex.

Finally, we remark that it follows immediately by induction that Theorems 2.1 and 2.2 hold for finite direct sums.

3. Normal structure and uniform convexity. As we mentioned in the preceding section, it follows from a result of [2] (Theorem 4.1) that every uniformly convex Banach space has normal structure. In this section we show that even if a Banach space is reflexive and has strictly convex norm, it may possess normal structure but not be isomorphic to any uniformly convex Banach space.

THEOREM 3.1. There exists a Banach space which is reflexive, strictly convex, and which possesses normal structure, but which is not isomorphic to any uniformly convex Banach space.

Proof. Let $p>1$ and consider the space $B$ of all sequences $x=$ $\left(x^{(1)}, x^{(2)}, \cdots\right)$ where each element $x^{(i)}$ is a Banach space $B^{(i)}$ and

$$
\sum_{1}^{\infty}\left\|x^{(i)}\right\|^{p}<\infty .
$$


Take

$$
\|x\|=\left(\sum_{1}^{\infty}\left\|x^{(i)}\right\|^{p}\right)^{1 / p} .
$$

We also assume that each of the spaces $B^{(i)}$ is finite dimensional, strictly convex, and restricted in such a way that $B$ is not isomorphic to any uniformly convex Banach space. (This involves conditions on the dimensions of $B^{(i)}$ and on their respective norm functions which have no bearing on the following argument; see Day [5, Th. 2].)

Suppose $K$ is a bounded convex subset of $B$ which consists entirely of diametral points. We show that this assumption leads to a contradiction if $\delta(K)>0$.

Let $\left\{x_{n}\right\}$ be a diametral sequence [3] in $K$ (that is, $d\left(x_{n+1}\right.$, conv $\left.\left\{x_{1}, \cdots, x_{n}\right\}\right) \rightarrow \delta(K)$ as $\left.n \rightarrow \infty\right)$. Since $K$ is bounded, $\left\{x_{n}^{(1)}\right\}$ is a bounded sequence in the finite dimensional space $B^{(1)}$ and thus it has a convergent subsequence $\left\{x_{1 n}^{(1)}\right\}$ which has limit, say $y^{(1)}$. By induction one may select a subsequence $\left\{x_{k n}\right\}$ of $\left\{x_{(k-1) n}\right\}$ such that if $i \leqq k$,

$$
\lim _{n \rightarrow \infty} x_{k n}^{(i)}=y^{(i)} \text {. }
$$

Using the way the sequence $y=\left(y^{(1)}, y^{(2)}, \ldots\right)$ is defined, one may obtain a subsequence $\left\{y_{n}\right\}$ of $\left\{x_{n}\right\}$ which has property:

$$
\lim _{n \rightarrow \infty} y_{n}^{(i)}=y^{(i)}, \quad(i=1,2, \cdots) .
$$

Furthermore, since $B$ is reflexive this subsequence may be chosen so that it converges weakly, say to $z$. Because of (1) it follows that $z^{(i)}=y^{(i)}$ and thus that $z=y$. Hence $y$ not only is in $B$, but it is in the closed convex hull of $\left\{x_{n}\right\}$.

Since $\left\{y_{n}\right\}$ converges weakly to $y, d\left(y, \operatorname{conv}\left\{y_{1}, \cdots, y_{n}\right\}\right) \rightarrow 0$ as $n \rightarrow \infty$. But $\left\{y_{n}\right\}$ is a subsequence of the diametral sequence $\left\{x_{n}\right\}$ so $d\left(y_{n+1}, \operatorname{conv}\left\{y_{1}, \cdots, y_{n}\right\}\right) \rightarrow \delta(K)$ as $n \rightarrow \infty$, and therefore

$$
\left\|y_{n}-y\right\| \rightarrow \delta(K) \text { as } n \rightarrow \infty \text {. }
$$

Now let $\varepsilon>0,3 \varepsilon<\delta(K)$. Integers $r, N>r, s>N$ may be chosen large enough that

$$
\begin{aligned}
& \left\|y_{r}-y\right\|>\delta(K)-\varepsilon,\left\|y_{s}-y\right\|>\delta(K)-\varepsilon, \\
& \sum_{1}^{N}\left\|y_{s}^{(i)}-y^{(i)}\right\|^{p}<\varepsilon^{p}, \text { and } \\
& \sum_{N+1}^{\infty}\left\|y_{r}^{(i)}-y^{(i)}\right\|^{p}<\varepsilon^{p} .
\end{aligned}
$$




$$
\begin{aligned}
\|x\|_{1, N} & =\left(\sum_{1}^{N}\left\|x^{(i)}\right\|^{p}\right)^{1 / p}, \\
\|x\|_{N+1} & =\left(\sum_{N+1}^{\infty}\left\|x^{(i)}\right\|^{p}\right)^{1 / p},
\end{aligned}
$$

it follows that

$$
\begin{aligned}
\left\|y_{s}-y_{r}\right\|^{p}= & {\left[\left\|y_{s}-y_{r}\right\|_{1, N}\right]^{p}+\left[\left\|y_{s}-y_{r}\right\|_{N+1}\right]^{p} } \\
\geqq & {\left[\left\|y_{r}-y\right\|_{1, N}-\left\|y_{s}-y\right\|_{1, N}\right]^{p} } \\
& +\left[\left\|y_{s}-y\right\|_{N+1}-\left\|y_{r}-y\right\|_{N+1}\right]^{p} \\
\geqq & {[\delta(K)-3 \varepsilon]^{p}+[\delta(K)-3 \varepsilon]^{p} . }
\end{aligned}
$$

Thus

$$
\sup \left\|y_{s}-y_{r}\right\| \geqq 2^{1 / p} \delta(K)>\delta(K)
$$

and we have a contradiction.

Although reflexivity of $B$ was useful in the above argument, normal structure is not implied by reflexivity or even by isomorphism with Hilbert space. For example, let $H$ be Hilbert space and $B$ the space isomorphic to $H$ with norm defined (for $x \in H$ ) by

$$
\|x\|=\sup \left\{1 / 2\|x\|_{H},\left|x_{n}\right|\right\} .
$$

Let

$$
K=\left\{x:\|x\| \leqq 1 \text { and } x_{i} \geqq 0 \text { for all } i\right\} .
$$

If $x$ and $y$ are in $K$, then $\|x-y\| \leqq \sup \{1,1\}=1$. Thus $\delta(K) \leqq 1$. Given $x$ in $K$ and $\varepsilon>0$, choose $y$ with a single nonzero component $y_{k}=1$ with $k$ chosen so that $\left|x_{k}\right|<\varepsilon$. Then

$$
\|x-y\| \geqq\left|x_{k}-y_{k}\right|>1-\varepsilon .
$$

Thus each point of $K$ is a diametral point of $K$.

We wish to thank the referee for the above example of a reflexive space which does not possess normal structure. (Another such example, due to R. C. James, was sent to us by Stanley Weiss.) We are also grateful to the referee for providing us with a much simpler proof of Theorem 3.1.

\section{REFERENCES}

1. L. P. Belluce and W. A. Kirk, Fixed-point theorems for families of contraction mappings, Pacific J. Math. 18 (1966), 213-218.

2. L. P. Belluce and W. A. Kirk, Nonexpansive mappings and fixed-points in Banach spaces, Illinois J. Math. 11 (1967), 474-479. 
3. M. S. Brodskii and D. P. Milman, On the center of a convex set, Dokl. Akad. Nauk SSSR (N.S.) 59 (1948), 837-840.

4. F. E. Browder, Nonexpansive nonlinear operators in a Banach space, Proc. Nat. Acad. Sci. 54 (1965), 1041-1044.

5. M. M. Day, Reflexive Banach spaces not isomorphic to uniformly convex spaces, Bull. Amer. Math. Soc. 47 (1941), 313-317.

6. R. DeMarr, Common fixed-points for commuting contraction mappings, Pacific J. Math. 13 (1963), 1139-1141.

7. W. A. Kirk, A fixed-point theorem for mappings which do not increase distances, Amer. Math. Monthly 72 (1965), 1004-1006.

Received October 11, 1966. This research was supported by the National Science Foundation, grants GP5994 and GP5967.

UNIVERSity OF CALIFORNIA, RIVERSIDE

University of NeW MeXico 


\section{PACIFIC JOURNAL OF MATHEMATICS}

\section{EDITORS}

\section{H. ROYDEN}

Stanford University

Stanford, California

R. R. Phelps

University of Washington

Seattle, Washington 98105

\section{J. DugundJI}

Department of Mathematics

University of Southern California

Los Angeles, California 90007

RICHARD ARENS

University of California

Los Angeles, California 90024

\section{ASSOCIATE EDITORS}
E. F. BeCKENBACH
B. H. NeumanN
F. WOLF
K. YosIDA

\section{SUPPORTING INSTITUTIONS}

\author{
UNIVERSITY OF BRITISH COLUMBIA \\ CALIFORNIA INSTITUTE OF TECHNOLOGY \\ UNIVERSITY OF CALIFORNIA \\ MONTANA STATE UNIVERSITY \\ UNIVERSITY OF NEVADA \\ NEW MEXICO STATE UNIVERSITY \\ OREGON STATE UNIVERSITY \\ UNIVERSITY OF OREGON \\ OSAKA UNIVERSITY \\ UNIVERSITY OF SOUTHERN CALIFORNIA
}

\author{
STANFORD UNIVERSITY \\ UNIVERSITY OF TOKYO \\ UNIVERSITY OF UTAH \\ WASHINGTON STATE UNIVERSITY \\ UNIVERSITY OF WASHINGTON \\ AMERICAN MATHEMATICAL SOCIETY \\ CHEVRON RESEARCH CORPORATION \\ TRW SYSTEMS \\ NAVAL WEAPONS CENTER
}

Mathematical papers intended for publication in the Pacific Journal of Mathematics should be in typed form or offset-reproduced, double spaced with large margins. Underline Greek letters in red, German in green, and script in blue. The first paragraph or two must be capable of being used separately as a synopsis of the entire paper. It should not contain references to the bibliography. Manuscripts, in duplicate if possible, may be sent to any one of the four editors. All other communications to the editors should be addressed to the managing editor, Richard Arens, University of California, Los Angeles, California 90024.

Each author of each article receives 50 reprints free of charge; additional copies may be obtained at cost in multiples of 50 .

The Pacific Journal of Mathematics is published monthly. Effective with Volume 16 the price per volume (3 numbers) is $\$ 8.00$; single issues, $\$ 3.00$. Special price for current issues to individual faculty members of supporting institutions and to individual members of the American Mathematical Society: $\$ 4.00$ per volume; single issues $\$ 1.50$. Back numbers are available.

Subscriptions, orders for back numbers, and changes of address should be sent to Pacific Journal of Mathematics, 103 Highland Boulevard, Berkeley 8, California.

Printed at Kokusai Bunken Insatsusha (International Academic Printing Co., Ltd.), 7-17, Fujimi 2-chome, Chiyoda-ku, Tokyo, Japan.

PUBLISHED BY PACIFIC JOURNAL OF MATHEMATICS, A NON-PROFIT CORPORATION

The Supporting Institutions listed above contribute to the cost of publication of this Journal, but they are not owners of publishers and have no responsibility for its content or policies. 


\section{Pacific Journal of Mathematics}

\section{Vol. 26, No. $3 \quad$ BadMonth, 1968}

Leonard Asimow, Universally well-capped cones ................. 421

Lawrence Peter Belluce, William A. Kirk and Eugene Francis Steiner,

Normal structure in Banach spaces ..................... 433

William Jay Davis, Bases in Hilbert space.................... 441

Larry Lee Dornhoff, p-automorphic p-groups and homogeneous

algebras..................................... 447

William Grady Dotson, Jr. and W. R. Mann, A generalized corollary of the

Browder-Kirk fixed point theorem ....................... 455

John Brady Garnett, On a theorem of Mergelyan ................. 461

Matthew Gould, Multiplicity type and subalgebra structure in universal

algebras............................................. 469

Marvin D. Green, A locally convex topology on a preordered space . . . . . 487

Pierre A. Grillet and Mario Petrich, Ideal extensions of semigroups . . . . . . 493

Kyong Taik Hahn, A remark on integral functions of several complex

variables ... . . . . . . . . . . . . . . . . . . . . . . . . . . . . . . . . . . . 509

Choo Whan Kim, Uniform approximation of doubly stochastic

operators..................................... 515

Charles Alan McCarthy and L. Tzafriri, Projections in $\mathscr{L}_{1}$ and

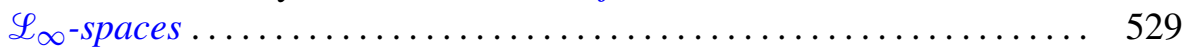

Alfred Berry Manaster, Full co-ordinals of RETs ................ 547

Donald Steven Passman, $p$-solvable doubly transitive permutation

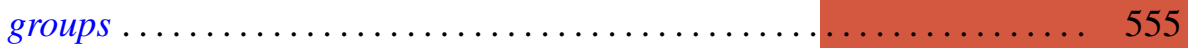

Neal Jules Rothman, An $L^{1}$ algebra for linearly quasi-ordered compact

semigroups ....................................... 579

James DeWitt Stein, Homomorphisms of semi-simple algebras .......... 589

Jacques Tits and Lucien Waelbroeck, The integration of a Lie algebra

representation ...............................

David Vere-Jones, Ergodic properties of nonnegative matrices. II ........ 601

Donald Rayl Wilken, The support of representing measures for $R(X) \ldots \ldots 621$

Abraham Zaks, Simple modules and hereditary rings .... . . 